\title{
ANDES

www.scielo.cl

\section{A setenta años del inicio de la vacunación antipertussis. Breve revisión histórica de los tratamientos empleados en su combate}

\author{
Seventy years after the beginning of vaccination against pertussis. \\ Brief historical review of the treatments used in its combat
}

\author{
Alejandro Donoso Fuentes ${ }^{a}$, Dina Contreras Esteyes ${ }^{b, c}$, \\ Daniela Ulloa Vega ${ }^{\mathrm{d}}$, Daniela Arriagada Santis ${ }^{\mathrm{a}}$
}

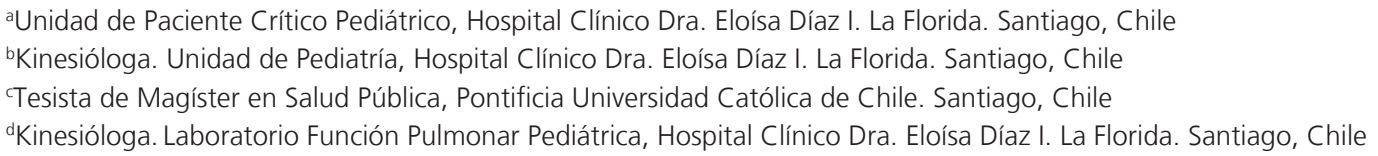

Recibido: 23 de septiembre de 2021; Aceptado: 29 de octubre de 2021

¿Qué se sabe del tema que trata este estudio?

El impacto benéfico de las inmunizaciones sobre las diversas enfermedades infecciosas, como lo ha sido en el caso de la coqueluche, es ampliamente valorado. Sin embargo, menos conocido es su tratamiento previo a la incorporación de la vacuna.

\section{¿Qué aporta este estudio a lo ya conocido?}

Nos recuerda desde una perspectiva histórica los esfuerzos realizados para la cura de esta grave enfermedad infecciosa. Todas estas medidas pertenecen al acervo cultural de la medicina como también al patrimonio sanitario nacional.

\section{Resumen}

Durante siglos fueron empleados numerosos tratamientos, de los más variados orígenes y basados en los más inverosímiles fundamentos, destinados a apresurar la recuperación y mejorar la sobrevida de los pacientes con coqueluche o tos convulsiva. En 1906 al identificarse el origen bacteriano de la coqueluche, surgió la esperanza de un potencial tratamiento, sin embargo, sólo décadas después la humanidad enfrentaría un cambio significativo con la consolidación de una vacunación efectiva. Este artículo entrega una mirada histórica del uso de algunos de los tratamientos más frecuentes ideados entre los siglos XVIII-XX para la cura de la tos convulsiva. Se enfatizan y detallan algunas de las terapias ofrecidas en Chile en la primera mitad del siglo pasado.

Correspondencia:

Alejandro Donoso Fuentes

adonosofuentes@gmail.com

Palabras clave: Bordetella Pertussis; Historia Pediatría; Infecciones; Epidemia; Tos Convulsiva 


\section{Abstract}

For centuries, numerous treatments were used, of the most varied origins and based on the most unlikely foundations designed to hasten recovery and improve the survival of patients with whooping cough. In 1906, when the bacterial origin of whooping cough was identified, the hope for a potential treatment arose, however, only decades later, humanity would face a significant change with the consolidation of an effective vaccination. This article provides a historical review from the use of some of the most frequent treatments devised between the 18th-20th centuries for the cure of whooping cough. Some of the therapies offered in Chile in the first half of the last century are emphasized and detailed.

\section{Keywords:}

Bordetella Pertussis;

Pediatric History;

Infections; Epidemic;

Whooping Cough

\section{Introducción}

Una década antes que falleciera en 1961, en la ciudad de Bruselas, el nonagenario microbiólogo e inmunólogo Jules Jean Baptiste Vincent Bordet (Figura 1), se inició en nuestro país la inmunización contra la tos convulsiva o coqueluche. Jules Bordet conjuntamente con Octave Gengou identificaron en 1906, mientras trabajaban en el Instituto Pasteur de París, el bacilo Gram negativo responsable de la tos convulsiva (Bordetella pertussis) que por aquella época presentaba una letalidad del $10 \%{ }^{1}$.

El positivo impacto de la vacunación contra la coqueluche iniciado en nuestro país en 1951, y la posterior introducción en 1971 de la vacuna triple bacteriana o DPT ("diphtheria, pertussis and tetanus whole-cell vaccine" $)^{2}$, apagó paulatinamente el gran temor parental en lo referente a la sobrevida de sus hijos, y así poco a poco fueron quedando atrás un sinnúmero de tratamientos empleados en las décadas previas.

El objetivo de esta investigación efectuada con ocasión del septuagésimo aniversario de la incorporación de la vacuna en Chile, es revisar los esfuerzos de la medicina para encontrar el alivio de síntomas y la cura de esta grave y aún vigente patología infecciosa.

\section{Antecedentes históricos}

Una de las primeras descripciones de la coqueluche data desde hace más de 1400 años atrás en China cuando fue descrita por Chao Yuanfang (550 d.C. - 630 d.C.), médico imperial de la Dinastía Sui, en el "Tratado sobre el origen y sintomas de las enfermedades". Es aquí donde se hace referencia a la "tos de los cien días", apareciendo mencionada en el capítulo de enfermedades de los niños, pero no en el de enfermedades de la tos. Concretamente el texto original señala ".... si la espalda del niño está fría, habría tos. Si esta no se cura dentro de un mes y hay una tos dentro de cien días, solo uno o dos de diez va a recuperarse".
Un registro preciso de los primeros casos en Occidente parece ser imposible, pues ya en el Medioevo existía falta de una nomenclatura médica unificada, identificándose con distintos nombres según la región.

En la Edad Moderna para la epidemia que se desarrolló en París en 1578 y la cual generó una gigantesca mortalidad, el afamado epidemiólogo Guillaume de Baillou (1538-1616) (Figura 1) describió su sintomatología, recibiendo la enfermedad el nombre de "Tussus Quintina"4.

Posteriormente, el médico inglés Thomas Sydenham (1624-1689), elaboró un escrito sobre la tos, y aunque en una oportunidad en el texto mencionó su nombre, no hizo comentario alguno 5 . Poco después, Thomas Willis (1621-1675) insistió en su peculiaridad epidémica, llamándola "Tussis Puerorum Seu Suflocativa"4.

\section{Tratamiento de la tos convulsiva en Europa}

\section{Siglos XVIII-XIX}

Para este período se puede mencionar una propuesta terapéutica según la fase de la enfermedad que cursaba el paciente ${ }^{6}$. Entre ellas destacan:

El tratamiento de Nils Rosén von Rosenstein (1706-1773), quien fue un médico y naturalista sueco, se basaba en aplicar consecutivamente: pantano-romero contra los "insectos" del miasma de la tos ferina, grasa de foca para el espasmo sofocante y finalmente, una mezcla de alquitrán y yema de huevo para acabar con la tos catarral residual ${ }^{6}$.

Por su parte el médico escocés William Cullen (1710-1790), se inclinaba para la primera fase por el uso de laxantes y ampollas aplicadas en el tórax para contrarrestar la "tendencia inflamatoria del pecho", además de eméticos con el objetivo de acortar los paroxismos y disminuir la frecuencia de la tos. Para la segunda fase, utilizaba tónicos: corteza de roble, muérdago y corteza peruana, y antiespasmódicos como cas- 


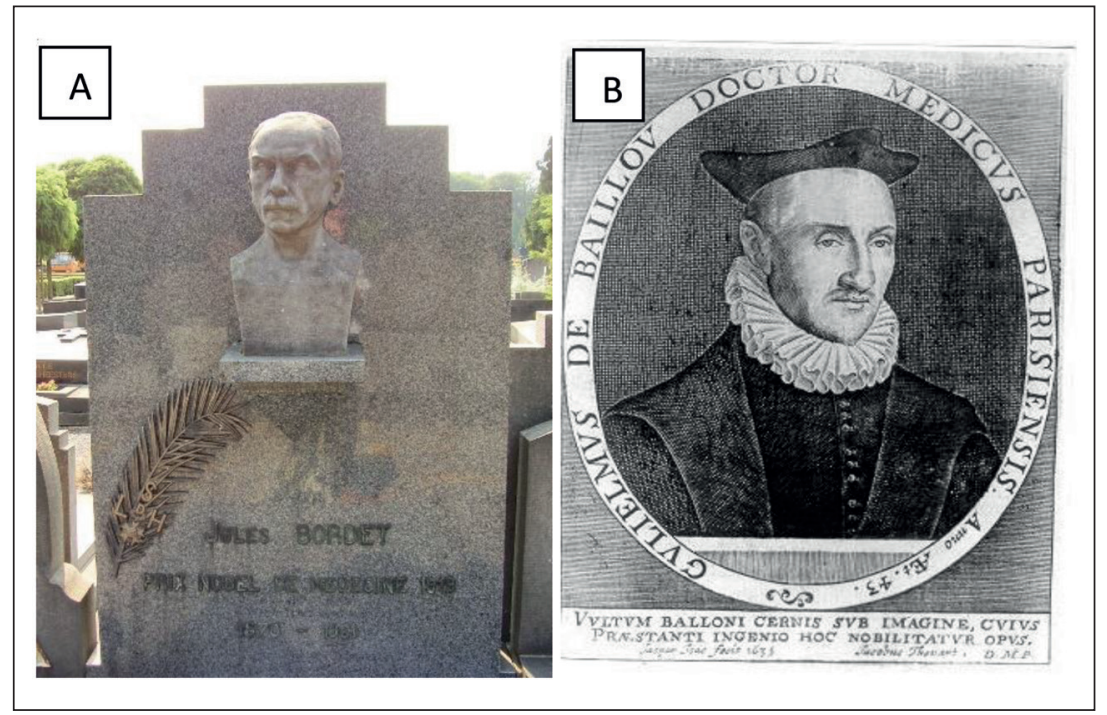

Figura 1. A. Jules Bordet (1870-1961). Cimetière d'Ixelles (Brucelas) B. Guillaume de Baillou (15381616). tóreo $^{\mathrm{i}}$, almizcle y cicuta (Conium maculatum). Cullen señaló además que la tos ferina podría tener un componente neuropático.

Christoph Wilhelm Hufeland (1762-1836), fue un eminente médico alemán quien recomendaba para la etapa de inflamación catarral un tratamiento consistente en el uso de laxantes y eméticos. Para ello se empleaba agua de hinojo (Foeniculum vulgare), jarabe de Maná, extracto de hiosciamina y antimonio. Posteriormente para el período paroxístico, aconsejaba el uso de plantas como asafétida (Férula assafoetida) y belladona (Atropa belladona) por enema; y finalmente en la tos grave sugería el uso de opio, aunque nunca de forma continua.

Charles-Michel Billard (1800-1832), uno de los primeros pediatras franceses, agregó para la fase paroxística una mezcla de óxido de zinc, belladona y cicuta. Para la fase final, en caso de persistir con síntomas recomendó la planta Cinchona, de ser necesario, con algunos fármacos antiespasmódicos. Si la tos continuaba con marcada expectoración de material mucopurulento, se pensaba que una preparación de musgo islandés era la mejor cura.

Otro pediatra francés fue Eugène Bouchut (18181891) quien sugirió para la fase inicial el uso de bebidas demulcentes, baños de pies y enemas. No obstante, solo recomendaba la flebotomía en niños robustos. En la segunda fase, sugería aplicar esparadrapos de mostaza o compresas de agua fría y vinagre en la frente en caso de congestión cerebral. Desaprobó el uso del opio, no así el uso de la belladona.

Edward G. Binz, en la segunda mitad del siglo XIX

iSecreción oleosa de las glándulas anales del castor. introdujo el uso de la quinina como tratamiento. A su vez, favoreció el uso de pequeñas dosis administradas a menudo al comienzo de la enfermedad, seguidas más tarde de dosis mayores a intervalos más largos. Con su utilización observó alivio de los accesos y una menor duración de la enfermedad".

Sin distinción de la fase en la que se utilizaba el tratamiento podemos encontrar:

\section{Uso de preparados de origen animal}

Hacia fines del siglo XVIII entre los tratamientos sugeridos provenientes de animales se proponía el uso de quilópodos como el ciempiés, coleópteros como las cantáridas o de ser posible el uso de patas de ternero. Además, se utilizaban derivados de órganos internos, entre ellos el extracto de vesícula biliar de buey ${ }^{7}$.

\section{Licor de alquitrán concentrado. Goudron de Guyot}

Este se obtenía de una maceración de alquitrán vegetal, más a menudo alquitrán de pino o alquitrán de Noruega. Esta droga se utilizó hasta principios del siglo XX y se le atribuyó virtudes terapéuticas contra la tos y cualquier malestar pulmonar. Se empleaba en bebidas a dosificación de una cucharada de café por vaso de agua (Figura 2).

\section{Jarabe de opio y heroína}

Durante el siglo XIX se comercializó el jarabe de opio, reseñado como "inocuo y agradable" para el tratamiento, e igualmente se recomendaba como tranquilizante para "niños revoltosos". Posteriormente, la farmacéutica Bayer comercializó el jarabe de heroína. (Figura 2). 

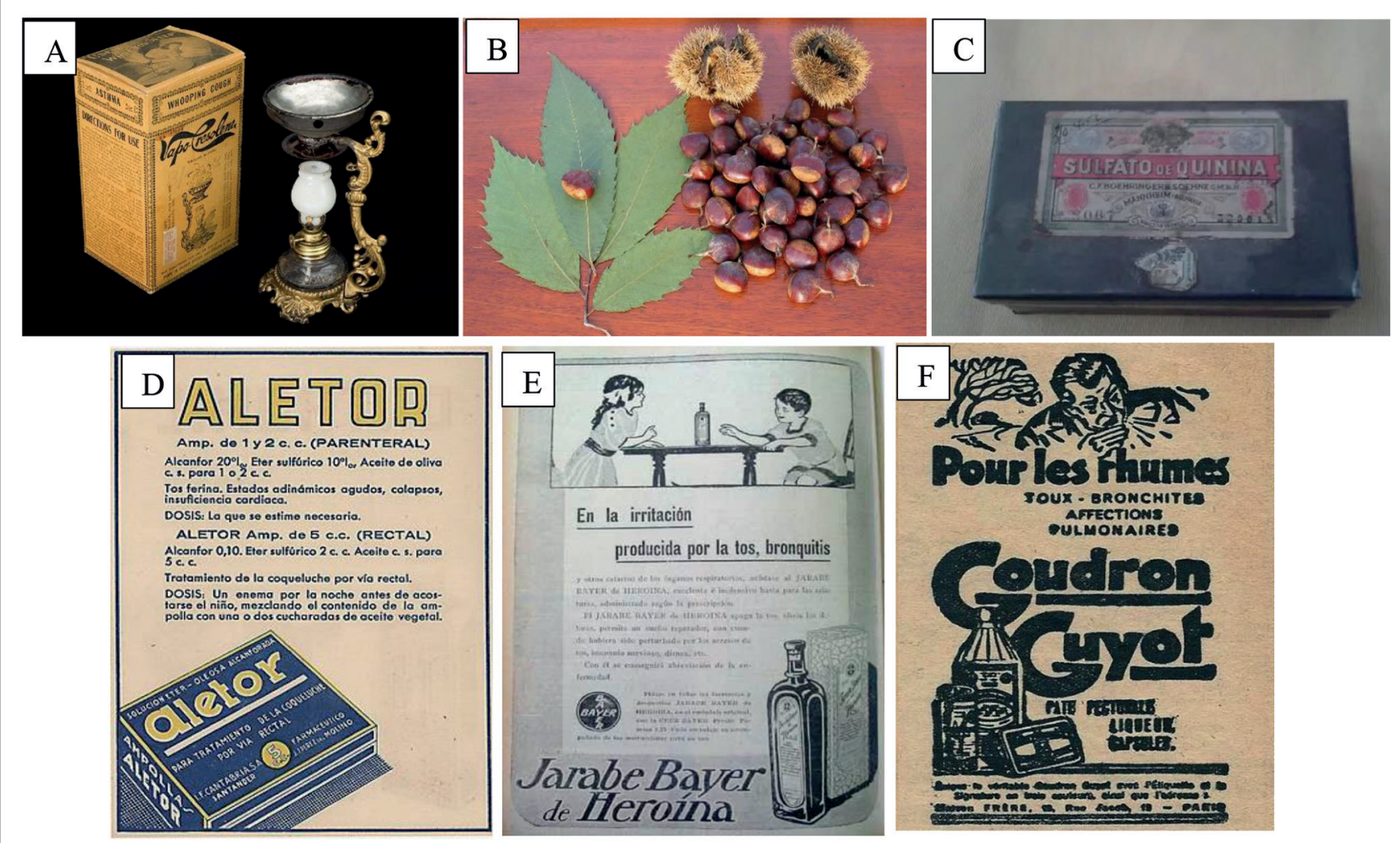

Figura 2. A: Vapo-cresolene-vaporizer; B: Castanea dentata; C: Sulfato de quinina D: Bromoferina; E: Jarabe de Heroína comercializado a partir de 1898, por la farmacéutica Bayer; F: Licor de alquitrán concentrado "Goudron de Guyot".

\section{Siglo XX}

\section{Cloroformo}

El cloroformo, administrado en inhalaciones durante los accesos de tos, se utilizó para disminuir la violencia de los espasmos de la glotis, sin embargo su gran limitación fue la necesidad de disponer de una persona capacitada para su administración en el hogar y la eventual culpabilización del agente por parte de la familia, como responsable de la muerte en pacientes más comprometidos ${ }^{8}$. En 1908 se publicó en la Revista de Medicina y Cirugía Prácticas, la experiencia del uso del cloroformo con resultado exitoso en cuatro enfermos de tos ferina. Además, se utilizaron las gotas Bami disminuyendo los ataques de tos y la adrenalina curando todos los casos al igual que la anestesia clorofórmica9. Dado lo anterior, es que se prefirió la adrenalina como tratamiento, para evitar los efectos indeseados del uso del cloroformo.

\section{Laurel cerezo de Grimault y Compañía}

Empleado para múltiples patologías del pulmón y la vía aérea. A su "delicioso sabor" se agregaba la ventaja de no tener opio ${ }^{10}$.

\section{Ozonoterapia}

Se recomendaba el uso de ozonoterapia durante 15 días con una inhalación diaria de 10 a 12 minutos, lo cual permitía acortar la duración de la enfermedad ${ }^{11,12}$.

\section{Lactoterapia e inyecciones de éter}

Dentro de las variadas indicaciones del uso de lactoterapia la cual tenía una gran aceptación por los médicos de la época ${ }^{6}$, estaba la coqueluche.

Por otra parte, el primero en introducir el tratamiento con inyecciones de éter fue Audrain en 1914, recomendando administrar por vía intramuscular una dosis de 1 a $2 \mathrm{ml}$, hasta tres veces al día ${ }^{13}$. Sin embargo, se señalaba que este método "causaba dolor y en ocasiones abscesos". No obstante, se sugería que de insistir el médico en esta opción terapéutica se podía aplicar por vía rectal con aceite en enemas, pues era más exitosa y permitía aliviar la sintomatología de la etapa paroxística $^{14}$.

\section{Hemoterapia}

Se pensaba que la administración temprana de inmunoglobulinas, reducía la gravedad y la duración de la fase paroxística de la enfermedad ${ }^{15}$. Décadas más tar- 
de (1991), en un estudio controlado realizado en Sue$\mathrm{cia}^{16}$, se encontraron resultados positivos asociados al uso de este tratamiento.

\section{Uso de productos derivados del carbón. Vaporizador Vapo-Cresolene}

Utilizado a fines del siglo XIX e inicios del XX (1910-1930) permitía aportar vapores antisépticos provenientes del alquitrán de hulla, indicándose que presentaba un rápido efecto, "en algunos segundos", y era efectivo en diversas enfermedades respiratorias, entre ellas la tos ferina. Se ofrecía en el mercado el tipo lámpara como también un nuevo modelo eléctrico. El Cresolene se produjo hasta 1957(Figura 2).

\section{Neumoterapia}

$\mathrm{Al}$ reconocer que los cultivos de Bordetella pertussis se veían favorecidos en su crecimiento mientras permanecían en un ambiente rico en $\mathrm{CO}_{2}$, nació la idea que una "aireación rápida" podría contribuir a disminuir su crecimiento. Es por esto que Nobécourt empleó la neumoterapia mediante baños de aire comprimido, "por su acción antiespasmódica y de sobreoxigenación de la sangre" 17,18 .

Chalamel en 1917 también utilizó la neumoterapia, en esta oportunidad a través del uso de automóviles alcanzando velocidades de hasta $145 \mathrm{~km} / \mathrm{h}$, para lograr de esta manera "apnea en el niño" que iba en el asiento delantero del vehículo ${ }^{19,20}$.

Una década más tarde, el médico militar Walter Matter realizó pruebas en niños durante su trabajo en la aviación, alcanzando alturas de hasta 2.500 a 3.000 metros en 10 a 15 minutos, y manteniéndose en esta por una hora. Luego se realizaban dos bruscos descensos de 500 metros cada uno para posteriormente recuperar la altura y poder descender a la misma velocidad con la que subió. Se debe señalar que el requisito para esta maniobra aeronáutica era que el avión estuviera descubierto o ampliamente comunicado con el exterior. Es así como el médico berlinés Kettner, decidió utilizar aviones cerrados y no obtuvo buenos resultados como tampoco la aprobación médica esperada.

\section{Cámara de descompresión}

En 1946 Baldry y Richou, realizaron en París el primer reporte de 300 casos tratados mediante una cámara de descompresión. En los años siguientes Richou, luego de tratar 6000 casos, concluyó: que los resultados obtenidos eran independientes de la edad, que el mejor tiempo de tratamiento correspondía entre 4 a 6 semanas, y que la repetición del tratamiento no incrementaba el porcentaje de éxito ${ }^{21}$.

\section{Uso de rayos $X$ y agentes radiactivos}

El uso de rayos X se llevó a cabo en las primeras dé- cadas del siglo XX en Estados Unidos y Europa ${ }^{\text {ii }}$. Este se asociaba con una marcada reducción en la mortalidad de niños menores de 3 años ${ }^{22}$ y alivio de los síntomas en aproximadamente el 85\% de los casos. La dosis de radiación empleada siempre correspondía a menos de 1.0 de dosis de eritema. No obstante, se señalaba cierto grado de preocupación por su empleo en lactantes dado la irradiación aplicada sobre el timo y tiroides.

El estudio pionero de los doctores Bowditch y Leonard (1923), quienes eran parte del staff médico del Floating Hospital en Boston ${ }^{23}$, señaló una mejoría en 21 de 26 personas en quienes se efectuó radiación en ambas caras del tórax, de modo alternante cada 48 a 72 horas completando un total de 3 a 4 dosis. Finalmente, en el Boston Floating Hospital (Figura 3) se trataron con rayos $\mathrm{X}$ a 850 pacientes con un éxito clínico constante, el cual se aproximaba al $80 \%{ }^{22}$.

Referente al mecanismo teórico en el cual se fundamentaba el uso de los rayos X, éste consistía en la reducción de la inflamación, logrando de esta manera disminuir el tamaño de los linfonodos hiliares ${ }^{24}$.

La radioactividad también se empleó para combatir la coqueluche. Específicamente se utilizaron inhalaciones de nitrógeno radiactivo. Éste se presentaba como un agente terapeútico de sólidas bases racionales y además carente de complicaciones como las observadas con el uso de narcóticos. El tratamiento duraba tres semanas, podía ser a domicilio y su costo estaba al "alcance de todas las fortunas".

\section{Infusión de Castaña}

En la práctica nativa americana se utilizaba la infusión de hojas de Castanea dentata (American Chestnut), para el tratamiento de la tos convulsiva ${ }^{25}$. Preparaciones similares se emplearon en Europa, mediante una infusión de hojas secas de Castaña dulce ${ }^{26}$ (Figura 2).

\section{Tratamiento osteopático}

Se encuentran recomendaciones sobre su uso durante el primer cuarto del siglo $\mathrm{XX}^{27}$, pues el tratamiento manipulativo osteopático era considerado parte del manejo de enfermedades infecciosas de la niñez en la era pre-antimicrobiana. Dentro de las técnicas comúnmente aplicadas estaban las de movilización y el drenaje linfático en la región cervical y torácica. Para el tratamiento de la cianosis podemos encontrar la siguiente cita datada en 1920 "Estire suavemente los músculos cercanos a las vértebras dorsales superiores. Aplique una toalla húmeda caliente que previamente se haya sumergido en agua hirviendo con vinagre y presiónela sobre la laringe del bebé después de que se enfríe un poco; un poco

iiNo se dispone, al revisar las publicaciones de la época, de una referencia específica sobre el primer caso reportado de tratamiento con rayos X. Probablemente esta fue entre 1907 y 1911 en la literatura científica rusa. 


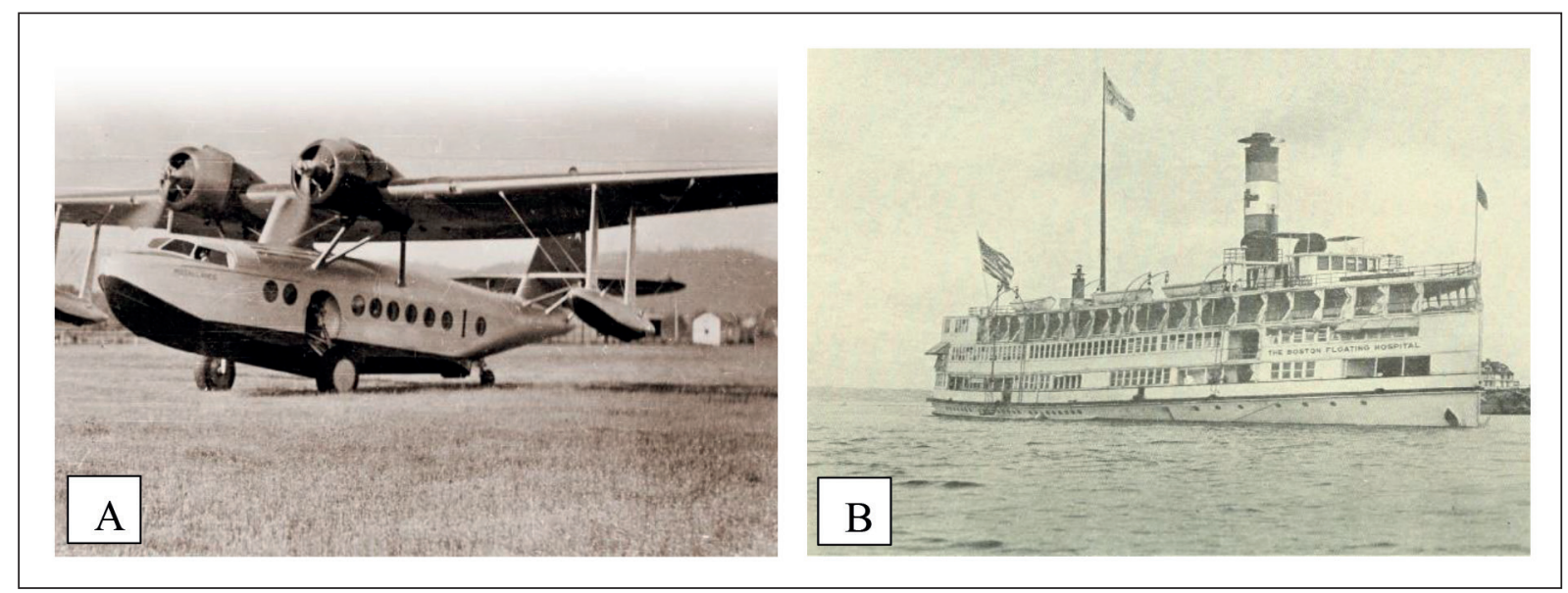

Figura 3. A. En 1935 se creó la Línea Aérea Experimental a Magallanes. El 21 de agosto de 1941, el bimotor «Magallanes» al momento de aterrizar en Bahía Catalina sufrió daños. A pesar de tener la intención de recuperarlo, esto nunca se concretó y se dio de baja a principios de 1945 B. El Hospital Flotante de Boston fundado por Rufus B. Tobey, ministro congregacional, en 1894.

más tarde, después del ataque, aplique tratamientos espinales suaves y manipulación externa de la laringe, tire del hueso hioides y la laringe hacia adelante"28.

\section{Algunos tratamientos utilizados en Chile}

\section{Siglo XIX}

\section{Ungüentos, jarabe del Dr. Danet, cochinillas y "Esencia de Mönckeberg"}

Según menciona el Dr. E. Laval ${ }^{4}$, el médico alemán Germán Schneider (1820-1884) quién se desempeñó desde mediados del siglo XIX en el sur de Chile, empleaba como tratamiento para la epidemia de tos convulsiva (1853) "un fuerte emético", "sangría", "sanguijuelas", "calomel"iii, "digital" y "ungüento de tártaro sobre el trayecto del pneumogástrico", entre otros. Aunque, también él mismo reconocía: ¡Qué remedios no han sido recomendados ya!

En un anuncio de medicamentos de origen francés distribuidos en Chile y publicado en 1864, se incluyeron los jarabes para niños del Dr. Danet, destinados a aliviar la coqueluche, la tos nerviosa y las convulsiones, entre otras dolencias ${ }^{29}$.

En el tratado completo de farmacia de Angel Vásquez $^{30}$ editado en Santiago en 1879, podemos encontrar diversas menciones para el tratamiento del coqueluche, entre ellas destacan:

Uso de ipecacuana (Bejuquillo, Raíz de oro, Raíz brasileña) como expectorante.

\footnotetext{
iii Calomel: mineral de cloruro de mercurio o mercurio córneo. Ampliamente utilizado como medicina en muy diversas enfermedades.
}

Sulfato de quinina (Figura 2) y acetato de morfina, presentes en las píldoras de Thorstein.

Café tostado, el cual era "preparado en agua, como se hace ordinariamente, aunque mucho más cargado".

Dentro de los insectos, específicamente en la orden hemíptera, la cochinilla (Coccus cacti) era considerada específica de la coqueluche, preparándose "1 gramo de esta, más 30 gramos de azúcar disuelta en agua fría y se dosifican en 3 cucharadas en veinticuatro horas".

\section{Aceite esencial de Ciprés}

Descubierto de un modo casual en Uruguay el año 1885 por el doctor J.J. Mönckeberg, al observar que un grupo de niños enfermos que jugaban en un terreno de plantación de Cipreses, presentaron una rápida mejoría de su sintomatología ${ }^{4}$.

Esta "Esencia de Mönckeberg" llegó a Chile en 1887 al comienzo de una nueva epidemia. José Manuel Bravo, médico chileno fue quien trató como primeros casos a una familia de tres niños y a la madre, todos en forma exitosa, utilizando inhalaciones "se ponen 15 a 20 gotas de esencia en la delantera y parte superior de los vestidos del niño. Repitiendo la operación cada vez que se había evaporado la esencia. Al mismo tiempo se usó en forma de jarabe, la administración de una cucharadita varias veces en el día, siendo mejor inmediatamente después de los accesos". La ventaja del aceite de Ciprés radicaba en la rapidez de su acción, fácil administración y carencia de efectos secundarios ${ }^{4,31}$.

\section{Siglo XX}

\section{Vuelos de altura}

El Dr. Pedemonte del Servicio de Pediatría del Hospital Regional de Puerto Montt, señaló en la Revista 
Chilena de Pediatría de 1940, el habérsele presentado la oportunidad de ocupar esta nueva modalidad de tratamiento en tres pacientes entre 7 meses y 3 años.

Esto fue posible gracias a la disponibilidad del avión anfibio Sikorsky "Magallanes" (Figura 3) que se encontraba en la ciudadiv. La duración del vuelo fue de 1 hora a 2800 metros de altura. A uno de los pacientes se le controló la presión arterial "observándose un leve aumento durante el ascenso". Los accesos de tos desaparecieron entre los 3 y 5 días en todos los pacientes.

\section{Sales de Bismuto}

La terapia con sales de bismuto (1943), nació de la observación de un paciente luético, quién al mismo tiempo que sufría de tos convulsiva, recibió terapia con sales de bismuto, comprobando con sorpresa que las quintas comenzaron a espaciarse y su estado general a mejorar.

Una experiencia nacional de 175 niños tratados por el Dr. Castro ${ }^{32}$ mencionó un efecto favorable para cualquiera de sus etapas. Se empleaba hidróxido de bismuto por vía intramuscular cada 48 horas durante 10 a 12 días (un 25\% abandonó el tratamiento después de la primera o segunda inyección). La serie clínica tuvo una mortalidad del 0,7\%, cifra notablemente baja en comparación a lo descrito en esa época (21\% en el primer año de vida y 4,5\% para los de 1 a 3 años).

ivEn 1935 se creó la Línea Aérea Experimental a Magallanes. El 21 de agosto de 1941, el bimotor «Magallanes» al momento de aterrizar en Bahía Catalina sufrió daños. A pesar de tener la intención de recuperarlo, esto nunca se concretó y se dio de baja a principios de 1945. Este hecho, marcó el fin del servicio aéreo militar entre Puerto Montt y Punta Arenas.

\section{Helioterapia}

Dentro de la pediatría ancestral como receta contra la tos convulsiva (luluchafo) y basado en la naturaleza divina del sol, encontramos que las madres mapuches "llevaban a los niños a la cumbre de un volcán para que jugasen todo un día bajo el sol"33.

\section{Comentario}

No existe evidencia en Chile de epidemias de coqueluche importantes entre el siglo XVI-XVIII, siendo las primeras en conocerse en detalle las ocurridas en las ciudades de La Serena (1851), Valdivia (1853) y Santiago, sucediendo esta última durante la década final del siglo $\mathrm{XIX}^{4}$.

Hacia mediados del siglo XX, mediante la incorporación de la vacuna anti-pertussis en nuestro país, se fue definitivamente relegando el arsenal terapéutico ofrecido a los niños por los médicos de la época, y a la vez que se consolidaba su trascendente rol en la escena sanitaria chilena.

El revisar épocas pretéritas donde el diagnóstico de la coqueluche era efectuado exclusivamente por los síntomas del paciente, examen físico y la experiencia del médico tratante, nos ha permitido conocer el variopinto tratamiento empleado con sus notables fundamentos y las existentes discrepancias entre los médicos, sobre los medios más adecuados para su combate; todo lo cual pertenece al acervo cultural de la historia de la medicina como también al patrimonio sanitario nacional.

\section{Conflicto de intereses}

Los autores declaran no tener conflicto de intereses.

\section{Referencias}

1. Dauer CC. Reported whooping cough morbidity and mortality in the United States, Public Health Rep. 1943;58:661-76.

2. Informe final programa nacional de inmunizaciones (PNI). En https://www. dipres.gob.cl/597/articles-139781_ informe_final.pdf. Accedido el dia 20 de Agosto 2021.

3. Liang Y, Salim AM, Wu W, Kilgore PE. Chao Yuanfang: Imperial Physician of the Sui Dynasty and an Early Pertussis Observer? Open Forum Infect Dis. 2016;3(1):ofw017.

4. Laval E. Contribución a la historia de la coqueluche en Chile. Siglo XIX. Rev Chil Infect 2010; 27 (4): 351-5.

5. Weston R. Whooping Cough: A Brief History to the 19th Century.
Can Bull Med Hist. 2012;29(2): 329-49.

6. Abt I. Treatment of whooping cough: a study in the history of therapeutics. Am J Dis Child. 1934;48(3):617-29.

7. Ahlstrom J. A Simple and Effectual Remedy, for St. Anthony's Fire and Whooping Cough in the Late Eighteenth Century. OAH Magazine of History 2005; 19(5):61-3.

8. Buscaglia F. La coqueluche y su tratamiento por el cloroformo: Tesis presentada para optar al título de doctor en medicina. Buenos Aires. 1907. En http://www.bibliomedicinadigital.fmed. uba.ar/medicina/TESISH/Tesis_01001_ La_coqueluche_por_cloroformo_ Buscaglia_Francisco_1907.pdf. Accedido el día 20 de agosto de 2021.

9. Feo F. Epidemia de coqueluche (tos ferina) en 1910 en Villardefrades (Valladolid). Papeles de Geografía 2010;51-52:329-6.

10. Cicarelli N. Ocurrió hace 100 años en medicina. http://www.bibliotecaminsal.cl/ wp/wp-content/uploads/2013/05/anales_ anos14y15_vol1_p171.pdf. Accedido el dia 20 de agosto 2021.

11. Fell G. The Clinical Advantages of Ozone and Its Effects on the Micro-Organisms of Infusions. Proceedings of the American Society of Microscopists 1883;5:69-77. doi: $10.2307 / 3220337$.

12. Martínez I. La ozonoterapia en la coqueluche. Barcelona, Asmarats, 1907; $82 \mathrm{pp}$.

13. Smith L. A review of the literature on whooping cough for the last five years, from 1919 to 1924. Am J Dis Child. 1924;28(5):597-617. 
14. Rada J. Tos ferina (Coqueluche). Rev. Soc. Boliv. Pediatr. 1996;35(2):53-8.

15. Islur J, Anglin CS, Middleton PJ. The whooping cough syndrome: A continuing pediatric problem. Clin Pediatr (Phila). 1975;14(2):171-6.

16. Granström M, Olinder-Nielsen AM, Holmblad P, Mark A, Hanngren K. Specific immunoglobulin for treatment of whooping cough. Lancet. 1991;338(8777):1230-3.

17. Banfi A. Coqueluche: tratamiento y complicaciones. Rev Chil Pediat 1975;46: 287-90.

18. Ledermann DW. Breve historia de la Bordetella pertussis, una elusiva damisela. Rev. chil. infectol. 2004;21(3):241-6.

19. Levent R. Le méthode de Strasbourg dans le traitement de la coqueluche. Gaz Hop 1947; 8: 121-2.

20. Evrard E, Simar A. Un cas grave de coqueluche traité par le vol en avion. Bruxelles Méd 1947; 12: 650-4.

21. Banks HS. High flying and decompression treatment of whooping-cough. Br Med J.
1949;2(4620):226.

22. Calabrese EJ, Dhawan G, Kapoor

R. Radiotherapy for Pertussis: An Historical Assessment. Dose Response. 2017;15(2):1559325817704760.

23. Bowditch HI, Leonard RD. Preliminary report on the treatment of pertussis by the X-ray. Bos Med Surg J. 1923;188(10):3123.

24. Bowditch HI. Further notes on the treatment of pertussis by theroentgen ray. JAMA. 1924;82(18):1422-4.

25. Hatfield G. Encyclopedia of Folk Medicine Old World and New World Traditions. Disponible en https://epdf. pub/encyclopedia-of-folk-medicine-oldworld-and-new-world-traditions.htmlAccedido el día 20 de Agosto de 2021.

26. Watts D. Dictionary of Plant Lore (1st Edition). United States: Editorial Elsevier Science Publishing Co Inc; 2007 pág 423.

27. Liem T. Osteopathic Manipulative Treatment for Pertussis in the 19th and 20th Centuries: A Structured Historical
Literature Review. J Am Osteopath Assoc. 2019;119(2):116-12.

28. Young CW. Little stories of the clinic: stories of the stuffed clinic. The Osteopathic Physican. 1920;38(1):2,4.

29. 143 "Célebres medicamentos franceses". En El Ferrocarril, Santiago, 8/nov./1864, p. 4.

30. Vázquez A. 1823-1893. Tratado completo de farmacia: Tomo 1. En en Memoria Chilena, Biblioteca Nacional de Chile http://www.memoriachilena.gob.cl/602/ w3-article-62246.html. Accedido en 9/7/2021. Accedido el dia 21 de agosto de 2021.

31. Bravo J. Tratamiento de la tos convulsiva por la esencia de Ciprés. Rev Méd Chile 1890-91; 19: 337-53.

32. Castro J. (1946). El bismuto en el tratamiento de la coqueluche. Rev. chil. pediatr. 1946;17(3):188-94.

33. Mora Z. El arte de sanar de la medicina mapuche. Antiguos secretos y rituales sagrados $1^{\circ}$ edición. Santiago de Chile:Uqbar Editores, 2012. 